\title{
Anti-Staphylococcal Activity of Cinnamomum zeylanicum Essential Oil against Planktonic and Biofilm Cells Isolated from Canine Otological Infections
}

\author{
Vinicius de Queiroz Albuquerque ${ }^{1}$, Maria Janeila Carvalho Soares ${ }^{2}$, Maria Nágila Carneiro Matos ${ }^{3}$, \\ Rafaela Mesquita Bastos Cavalcante ${ }^{3}$, Jesús Alberto Pérez Guerrero ${ }^{3}$, Tigressa Helena Soares Rodrigues ${ }^{4}$, \\ Geovany Amorim Gomes ${ }^{4}$, Rodrigo Fonseca de Medeiros Guedes ${ }^{5}$, \\ Débora de Souza Collares Maia Castelo-Branco ${ }^{5}{ }^{-}$, Isaac Neto Goes da Silva ${ }^{1}$ and Victor Alves Carneiro ${ }^{2,3, *}$
}

\section{check for}

updates

Citation: Albuquerque, V.d.Q.;

Soares, M.J.C.; Matos, M.N.C.;

Cavalcante, R.M.B.; Guerrero, J.A.P.;

Soares Rodrigues, T.H.; Gomes, G.A.;

de Medeiros Guedes, R.F.;

Castelo-Branco, D.d.S.C.M.; Goes da

Silva, I.N.; et al. Anti-Staphylococcal Activity of Cinnamomum zeylanicum

Essential Oil against Planktonic and

Biofilm Cells Isolated from Canine

Otological Infections. Antibiotics 2022

11, 4. https://doi.org/10.3390/

antibiotics 11010004

Academic Editors: William N. Setzer and Noura Dosoky

Received: 11 November 2021

Accepted: 7 December 2021

Published: 22 December 2021

Publisher's Note: MDPI stays neutral with regard to jurisdictional claims in published maps and institutional affiliations.

Copyright: (c) 2021 by the authors Licensee MDPI, Basel, Switzerland. This article is an open access article distributed under the terms and conditions of the Creative Commons Attribution (CC BY) license (https:/ / creativecommons.org/licenses/by/ $4.0 /)$
1 Department of Veterinary Sciences, State University of Ceará-Itaperi Campus, Fortaleza 60714-903, Brazil; viniciusqalbuquerque@gmail.com (V.d.Q.A.); isaac.neto@uece.br (I.N.G.d.S.)

2 Center for Bioprospecting and Applied Molecular Experimentation (NUBEM), University Center INTA-UNINTA, Sobral 62050-100, Brazil; janeilacarvalho29@gmail.com

3 Laboratory of Biofilms and Antimicrobial Agents (LaBAM), Federal University of Ceará, Sobral 62048-280, Brazil; nagilacarneirobio@gmail.com (M.N.C.M.); rafaelabastos.ufc@gmail.com (R.M.B.C.); jesus24p@gmail.com (J.A.P.G.)

4 Center of Exact Science and Technology, State University of Acaraú Valley, Sobral 62040-370, Brazil; thelenasr@yahoo.com.br (T.H.S.R.); pesquisadorgeo@yahoo.com.br (G.A.G.)

5 Group of Applied Medical Microbiology, Microbiology Department, Federal University of Ceará, Fortaleza 60430-160, Brazil; fmg_rodrigo@hotmail.com (R.F.d.M.G.); deb_castelobranco@yahoo.com (D.d.S.C.M.C.-B.)

* Correspondence: victor.carneiro@uninta.edu.br

\begin{abstract}
The aim of this study was to evaluate the phytochemical profile of Cinnamomum zeylanicum essential oil (CZEO) and their antimicrobial and antibiofilm activity against Staphylococcus strains isolated from canine otitis. First, the CZEO chemical composition was determined by gas chromatographymass spectrometry (CG-MS). External otitis samples collected from dogs were submitted to staphylococcal isolation, followed by MALDI-TOF mass spectrometry identification. The antimicrobial action was tested against the isolates using the disk-diffusion and microdilution methods. The antibiofilm activity was evaluated by CZEO-based concentrations, subMIC for biofilm formation and supraMIC against preformed biofilm, quantified by crystal violet (CV) staining and CFU counting The chemical analysis revealed that (E)-cinnamaldehyde, eugenol and (E)-cinnamyl acetate were the main compounds in the CZEO, representing 77.42, 8.17 and $4.50 \%$, respectively. Two strains of three different species, S. saprophyticus, S. schleiferi and S. pseudintermedius, were identified. The disk-diffusion test showed an inhibitory zone diameter, ranging from 34.0 to $49.5 \mathrm{~mm}$, while the MIC and MBC values were around 500 and $1000 \mu \mathrm{g} / \mathrm{mL}$. SubMIC demonstrated an inhibition on biofilm formation against 4 out the 6 strains tested. On mature biofilm, the CZEO-based supraMIC groups had slightly change on biomass, however, the biofilm cell viability decreased the CFU in 3 magnitude orders.
\end{abstract}

Keywords: natural product; antibiofilm activity; Staphylococcus spp.; canine-ear infections

\section{Introduction}

Otitis-related problems are one the most common diseases observed in canine patients, which cause inflammation of the ear membranes due to the uncontrolled growth of pathogenic bacteria and fungi [1]. Among bacterial agents, Staphylococcus strains are frequently associated with these infections, even though they are commensally present in small numbers on the skin and mucous membranes in healthy dogs [2]. When these bacteria become numerous, infections such as pyoderma and otitis media or externa may develop and prolong inflammation $[3,4]$. 
In those cases, antibiotics are the most common medication for domestic animals, yet they are also the most frequently misused. The indiscriminate use of antibiotics to prevent, control, and treat infections caused by microorganisms has allowed the emergence and spread of microbial mechanisms of resistance [5]. For instance, the prevalence of penicillinderived antibiotics resistance in Staphylococcus isolates obtained from canine and feline infections, such as methicillin-resistant Staphylococcus (MRS), has increased continuously over the last several decades [6]. Another factor that contributes to antibiotic resistance of staphylococcal strains is the formation of biofilms [7]. These biofilms are associated with the adhesion and colonization of different surfaces that also serve as physical and chemical barriers against the action of antimicrobial agents [8]. As antibiotic resistance continues to evolve, antibiotics of so-called last resort become even more precious. Reducing or preventing the dissemination of antibiotic resistance genes into human pathogens is currently of high international importance.

To date, it has not been found a solution solve the antibiotic resistance problem. Essential oils (EO), their main constituents, and most recently their association with antibiotics have been widely studied as promising therapeutic alternatives against different species of the Staphylococcus genus [9,10]. Studies exploring veterinarian applications of EOs as antimicrobials to treat microorganisms that cause skin infections in dogs are incipient, but promising [11,12]. The aim of this study was to evaluate the antimicrobial and antibiofilm activity of Cinnamomum zeylanicum EO (CZOE) against Staphylococcus sp. strains isolated from dogs with otitis infection.

\section{Results}

\subsection{Staphylococcal Strains}

Two strains of three Staphylococcal species were isolated and identified as S. pseudintermedius, S. schleiferi, and S. saprophyticus. Five of the six isolates presented resistance for at least one antibiotic, except for $S$. schleiferi 1 , which was sensitive against all the antibiotics tested. The most striking result was the strain S. pseudintermedius 1 which exhibited multiresistance to five antibiotics. The Staphylococcal strains identification and resistance profile are described below (Table 1).

Table 1. Staphylococcus isolates identification and resistance profile by MALDI-TOF mass spectrometry and disk-diffusion assay, respectively.

\begin{tabular}{ccc}
\hline Sample & MALDI-TOF ID & Resistance Profile \\
\hline 1 & S. saprophyticus 1 & PEN \\
2 & S. saprophyticus 2 & AZI, ERI, CLO \\
3 & S. schleiferi 1 & \\
4 & S. schleiferi 2 & SUT \\
5 & S. pseudintermedius 1 & CIP, SUT, TET, PEN, CLI \\
6 & S. pseudintermedius 2 & TET, CLO \\
\hline
\end{tabular}

Antibiotics panel: PEN: penicillin. AZI: azithromycin. ERI: erythromycin. CLO: chloramphenicol. SUT: sulfazotrim. GEN: gentamicin. CIP: ciprofloxacin. TET: tetracycline. CLI: clindamycin.

\subsection{CZEO Chemical Composition}

It was identified 11 compounds, $100 \%$ of the constituents, in the CZEO. The composition and chemical structures of the main constituents are presented in Figure 1. The CZEO consisted mainly of (E)-cinnamaldehyde $(77.42 \%)$, which together with eugenol and (E)-cinnamyl acetate accounted for more than $90 \%$ of the oil's composition. The remaining fraction was constituted by oxygenated monoterpenes, sesquiterpenes hydrocarbons and traces of benzenoids and monoterpenes. The Kovats indices from the literature (KIL) and the Kovats indices calculated (KIC) against n-alkanes (C7-C30) on an RTX-5MS column are available as Appendix A. 


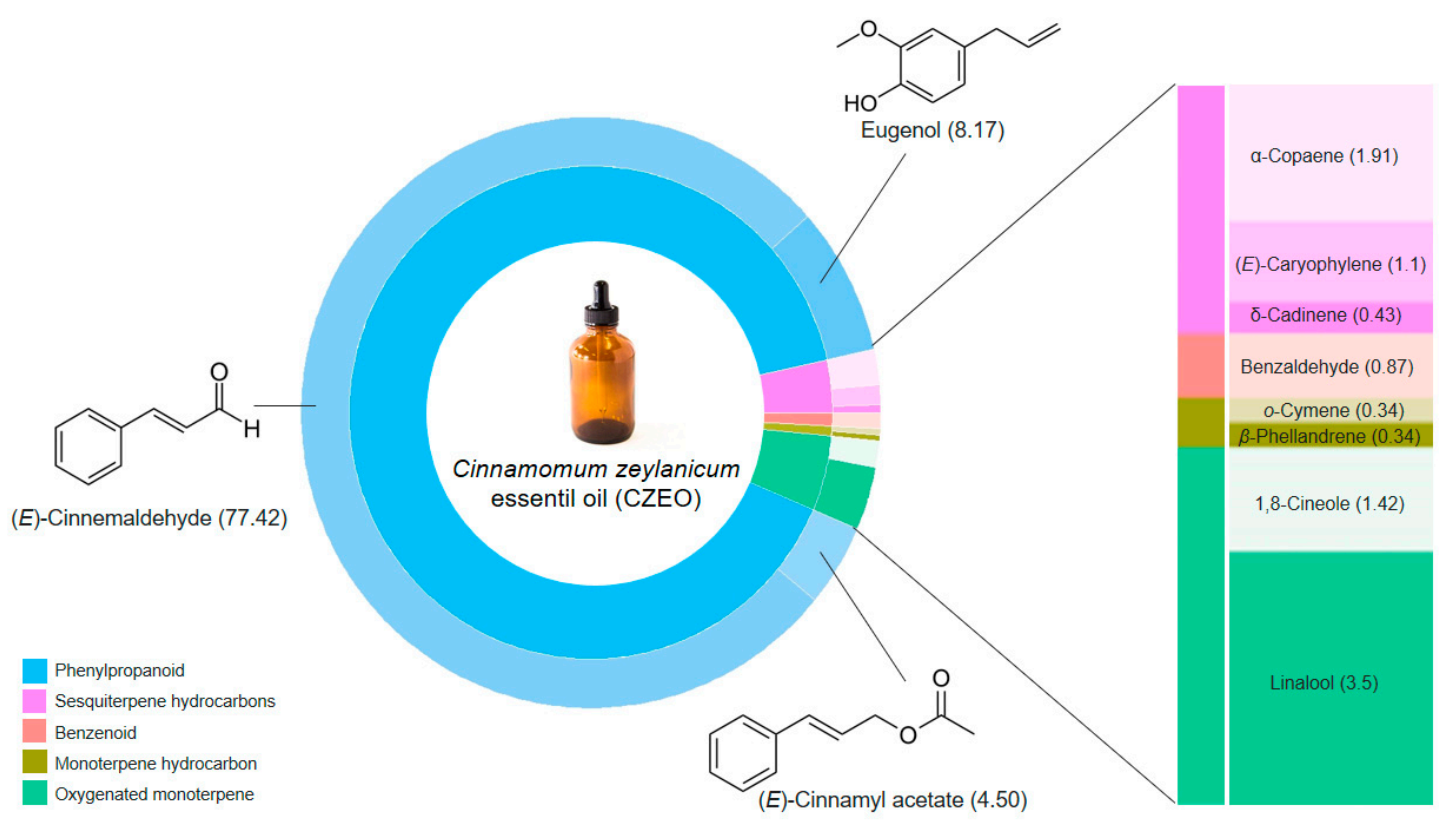

Figure 1. Percentage of the chemical compositions of the Cinnamomum zeylanicum essential oils (CZEO) and chemical structures of the main constituents.

\subsection{Antimicrobial Activity}

The CZEO demonstrated antimicrobial activity against all the Staphylococcus strains. The inhibitory parameters are shown in Table 2. Both S. saprophyticus strains showed the higher IZD, MIC, and MBC values, while S. schleiferi and S. pseudintermedius strains displayed moderate action with lower values for the same parameters.

Table 2. Inhibitory zone diameter (IZD), minimum inhibitory concentration (MIC) and minimum bactericidal concentration (MBC) of the Cinnamomum zeylanicum essential oil (CZEO) for the Staphylococcus strains.

\begin{tabular}{cccc}
\hline $\begin{array}{c}\text { Staphylococcus } \\
\text { Strains }\end{array}$ & IZD $(\mathbf{m m})$ & MIC $(\mu \mathbf{g} / \mathbf{m L})$ & MBC $(\mu \mathrm{g} / \mathbf{m L})$ \\
\hline S. saprophyticus 1 & $49.5 \pm 2.1$ & 1000 & 1000 \\
S. saprophyticus 2 & $49.0 \pm 0.1$ & 1000 & 1000 \\
S. schleiferi 1 & $34.0 \pm 2.0$ & 500 & 500 \\
S. schleiferi 2 & $39.0 \pm 2.8$ & 500 & 500 \\
S. pseudintermedius 1 & $35.0 \pm 4.2$ & 500 & 500 \\
S. pseudintermedius 2 & $36.0 \pm 0.1$ & 500 & 500 \\
\hline
\end{tabular}

\subsection{Antibiofilm Activity}

On average, CZEO-treated strains at subMIC had their biofilm formation inhibited (Figure 2). Both S. saprophyticus strains showed the highest biomass reduction, up to $85 \%$ at 1-MIC value. Although S. pseudintermedius strains were less affected by the CZEO, they also showed a reduction in biomass ( 80 and $50 \%$ ) when treated with EO at $\frac{1}{2}$ and 1-MIC values. Finally, the results did not reveal significance difference for $S$. schleiferi strains at subMIC concentrations. 


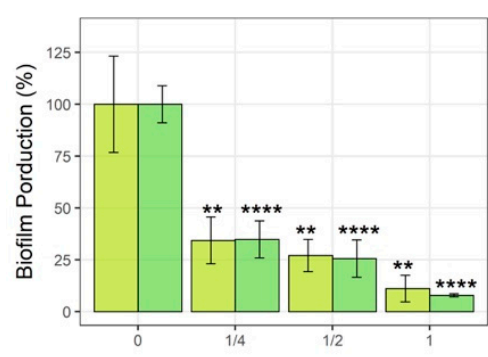

$\square$ S. saprophyticus $1 \square$ S. saprophyticus 2

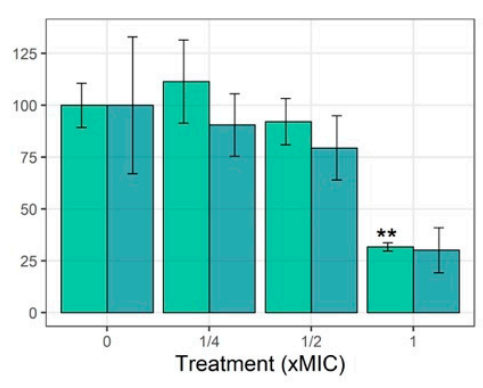

$\square$ S. schleiferi $1 \square$ s. schleiferi 2

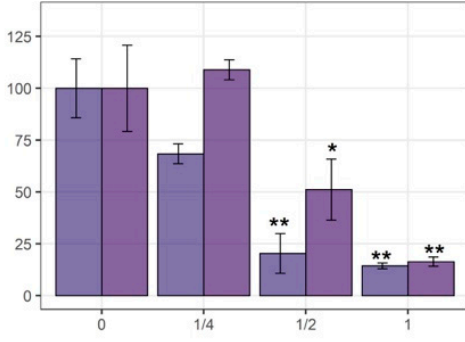

$\square$ S. pseudintermedius $1 \square$ S. pseudintermedius 2

Figure 2. Percentage of inhibition of Staphylococcus biofilm formation growth simultaneously with sub-inhibitory concentration ( $\frac{1}{4}-, \frac{1}{2}$ - and 1-fold of MIC) of Cinnamomum zeylanicum essential oil (CZEO) during $24 \mathrm{~h}$. Statistically different by one-way ANOVA with Tukey post hoc test $\left({ }^{*} p<0.05,{ }^{* *}\right.$ $\left.p<0.01 ;{ }^{* * * *} p<0.0001\right)$ compared to untreated cells.

According to preformed biofilm, overall, there was a positive correlation between the CZEO concentration and the reduction of biomass and viable cells of biofilm (Figure 3). The results showed that 4 of the 6 strains reduced their biomass when treated with CZEO. Interestingly, high concentration of CZEO did not decrease the biomass of S. saprophyticus 1 and S. schleiferi 2. Substantial reduction of viable cells, up to three orders in magnitude, was found for both S. saprophyticus and S. schleiferi 1 at 4 -fold MIC. While, similar results were reported for both S. pseudintermedius strains, no signs of reduction in CFU counting was found for schleiferi 2 .

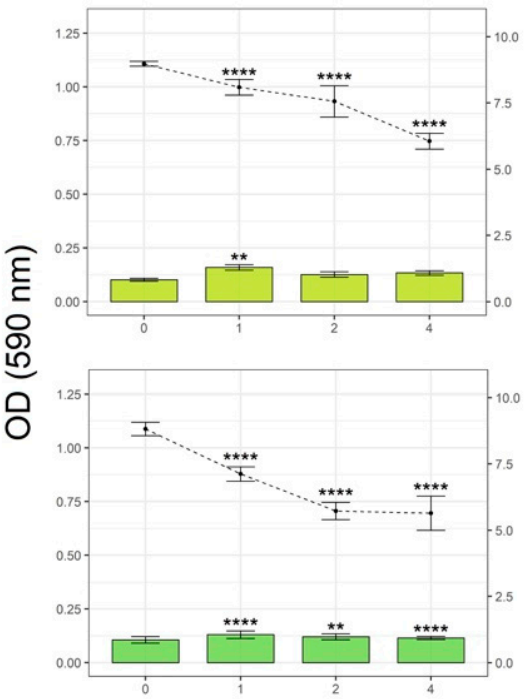

$\square$ S. saprophyticus $1 \quad \square$ S. saprophyticus 2
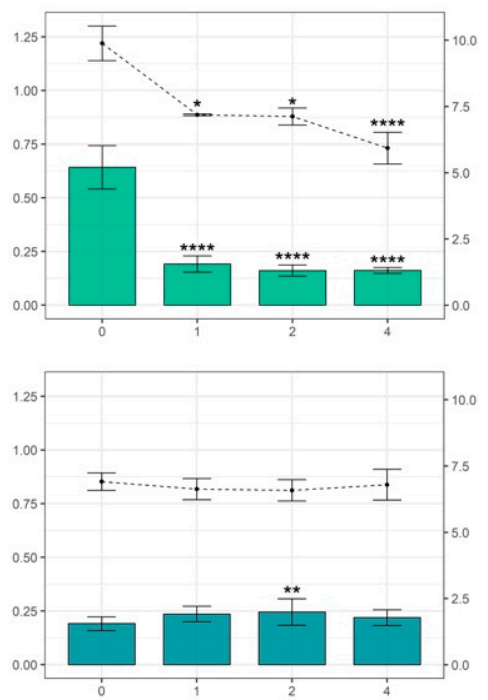

Treatment (xMIC)

S. schleiferi 1

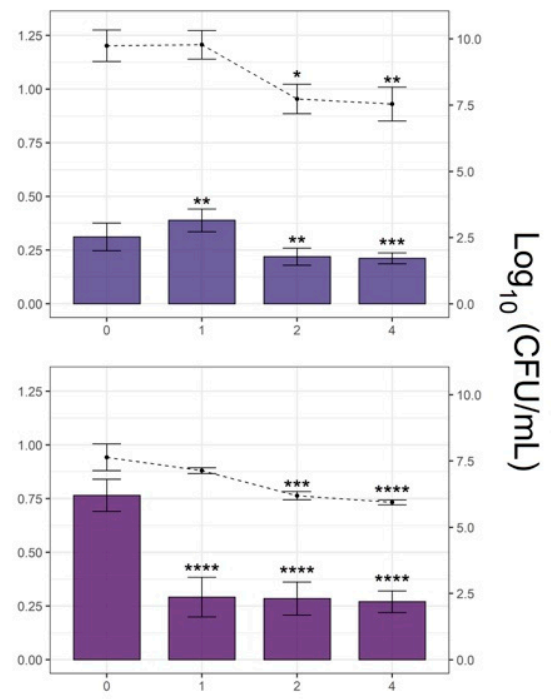

$\square$ S. pseudintermedius $1 \square$ S. pseudintermedius 2

Figure 3. Activity of different concentrations (1-, 2- and 4-fold of MIC) of Cinnamomum zeylanicum essential oil (CZEO) against Staphylococcus preformed biofilm after $4 \mathrm{~h}$ of treatment. Biomass quantification by crystal violet staining (OD $590 \mathrm{~nm}$, bars) and colony counting ( $\log _{10} \mathrm{CFU} / \mathrm{mL}$, lines). Statistically different by one-way ANOVA with Tukey post hoc test $\left({ }^{*} p<0.05 ;{ }^{* *} p<0.01 ;{ }^{* * *} p<\right.$ $0.001 ; * * * * 00.0001)$ compared to untreated cells.

\section{Discussion}

This study shows that CZEO was composed mostly by phenylpropanoids, specifically $(E)$-cinnamaldehyde $(77.42 \%)$, eugenol $(8.17 \%)$, and $(E)$-cinnamyl acetate $(4.50 \%)$. These results agreed with the major components reported for CZEO chemical composition [11,12]. The potential use of $(E)$-cinnamaldehyde and eugenol, regardless their origin, 
has been quite explored due to significant broad-spectrum activity against pathogenic bacteria $[13,14]$. Their action is frequently associated with the modulation of the structural properties of the cell surface, permeability and damaged, whether cell wall or plasmatic membrane level [15-17], although the contribution of the non-major components in the essential oil's antimicrobial effect still remains unclear.

The indiscriminate use of antibiotics in both human and veterinary medicine has caused a chain reaction for the appearance of multidrug-resistant (MDR) microorganisms to conventional treatments [18]. Not only all staphylococcal species isolated in this study are frequently described as etiological agents of ear canine infection [19], but also five out of the six strains were resistant to at least one antibiotic and three of them displayed a multidrugresistance profile. The CZEO antimicrobial activity ranged from 500 to $1000 \mu \mathrm{g} / \mathrm{mL}$ and is consistent with previous results from the Cinnamomum genus, which can reach until $1250 \mu \mathrm{g} / \mathrm{mL}$ [20]. Although the antimicrobial effect can be associated with the presence of the major components of EO, or even an interaction between their components; further work needs to be done to establish exactly the mechanism of action and the components responsible for the antimicrobial effect.

Despite the efforts on exploring essential oils and their antimicrobial activity, the antibiofilm effect has been less evaluated [10,21-23]. In this study, we analyzed the CZEO ability to inhibit biofilm formation and we found that CZEO interfered on most staphylococcal biofilm, five of six strains tested (Figure 2). This action can be related to the antimicrobial action against planktonic cells in the first inoculum, resulting in a lower cell viability and minor biofilm attachment $[24,25]$. Nevertheless, should be considered the cinnamaldehyde effect on quorum sensing, system of bacterial communication that regulates the biofilm formation, previously reported in S. aureus strains [26]. Thus, this molecule could also play an important anti-biofilm activity, since it reaches more than $77 \%$ of CZEO composition.

The physical tolerance promoted mainly by EPS (exopolysaccharide) production is crucial to restrict the penetration and diffusion of antimicrobials, protecting the cells against hostile environment [8]. Thus, the antimicrobial ability against preformed (mature) biofilm is an important parameter to measure promising approaches for biofilm eradication [27]. Regarding to mature biofilm, our results showed that four of the six strains reduced their biomass when treated with CZEO. Interestingly, the strains with the highest biofilm production, S. schleiferi 1 and S. saprophyticus 2, displayed more reductions in biomass with values above $60 \%$, even when treated with lower EO concentration (Figure 3). Although there are several possible explanations for this outcome, we suggest that larger tridimensional biofilm structures may be more impacted by antibiofilm agents due to increase in surface area increasing the direct killing of biofilm-embedded bacteria, as it has been demonstrated in other studies $[16,28]$.

In addition to the mature biofilm reduction, the CFU counting shows that $\mathrm{EO}$ effect is directly related to bacterial death, being proportional to the oil concentration (Figure 3). This is relevant since some cells into biofilm deep layers can show a persistence profile, also known as slow-dividing bacteria, and consequently are less susceptible to antibiotics [29]. Thus, the findings support the idea that natural-based compounds are a great source of new strategies to fight against resistant bacteria and eliminate microbial biofilms [30]. Studies relating natural plant products as new alternatives to combat MDR bacteria have gained researchers attention to develop creams and gels for topical applications [31,32]. EOs, widely commercialized, have become a viable alternative for the development of new treatments against skin infections in veterinary medicine, including pyoderma, media- and external-otitis [11].

\section{Materials and Methods}

\subsection{Staphylococcal Strains}

Ear-secretions samples from dogs with clinical signs for otitis externa were collected using sterile cotton swabs in a veterinary clinic localized in Fortaleza, Brazil. The sam- 
ples were initially inoculated on blood agar and incubated aerobically for $24 \mathrm{~h}$ at $37^{\circ} \mathrm{C}$. Suspected colonies were submitted to presumptive Staphylococcus identification through selective medium culture, Mannitol Salt Agar (KASVI, São José dos Pinhais, Paraná, Brazil) and Baird Parker Agar (Acumedia, Lansing, MI, USA), colony morphology, Gram staining and coagulase test. The isolates were finally submitted to a Matrix-Assisted Laser Desorption/Ionization-MALDI (Bruker Daltonik MALDI Biotyper) mass spectrometry identification [33]. The isolates resistance profile was determined by the disk diffusion method against antibiotics panel, following the protocols of the Clinical and Laboratory Standards Institute [34]. The strains were stored in Tryptic Soy Broth (TSB, KASVI, São José dos Pinhais, Paraná, Brazil) with glycerol at $-20{ }^{\circ} \mathrm{C}$.

\subsection{Culture Conditions}

From stock cultures, the strains were activated inoculating $50 \mu \mathrm{L}$ into $5 \mathrm{~mL}$ of TBS and incubated at $37^{\circ} \mathrm{C}$ for $24 \mathrm{~h}$ in aerobic conditions. Next, $50 \mu \mathrm{L}$ were inoculated in fresh medium (1:100) and grown until the end of the exponential phase. Bacterial cells were adjusted compared to the McFarland 0.5 turbidity standard $\left(1 \times 10^{8} \mathrm{CFU} / \mathrm{mL}\right)$ and diluted with suitable media to reach the appropriate cell concentration for each method.

\subsection{Oil Acquisition and Manipulation}

The CZOE was purchased from Laszlo ${ }^{\circledR}$ aromatherapy company (Belo Horizonte, Brazil). According to the manufacturer, the $\mathrm{CZEO}$ was extracted from the stem bark of C. zeylanicum plant from Sri Lanka using steam distillation. CZEO stock solution was prepared at $16,000 \mu \mathrm{g} / \mathrm{mL}$ in sterile TSB at $1 \%$ tween 80 (Sigma Aldrich ${ }^{\circledR}$, Saint Louis, MO, USA). Free-EO TSB at $1 \%$ tween 80 was used as control.

\subsection{Determination of CZEO Chemical Composition}

The volatile oil was analyzed by gas chromatography-mass spectrometry (GC-MS) and gas chromatography with flame ionization detection (GC-FID). The qualitative and quantitative analysis of the oil was performed using a Shimadzu single quadrupole GCMSQP2010 gas chromatograph coupled to VG Analytical 70-250 S mass spectrometer and a flame ionization detector (FID). The percentage of constituents was calculated through the integral area of their respective peaks, related to the total area of all constituents in the sample. The different EOs' constituents were identified by visually comparing their mass spectra provided by the equipment's databases (NIST08) as well as by comparison of the calculated retention indices to those available in the literature [35]. A standard solution of n-alkanes (C7-C30) was injected under the same chromatographic conditions as the sample and was used to obtain the retention indices as described by Van den Dool and Kratz [36].

\subsection{CZEO Antimicrobial Activity}

\subsubsection{The Aromatogram Method}

The CZEO antimicrobial activity was performed as in traditional antibiotic susceptibility testing using the disc diffusion test [37], known as the aromatogram method [38]. Cottontipped swabs dipped into a standardized bacterial suspension adjusted at $1 \times 10^{8} \mathrm{CFU} / \mathrm{mL}$ were streaked on Mueller Hinton agar plates (MHA, Acumedia ${ }^{\circledR}$, Lansing, MI, USA) to cover the entire surface. After plate drying, $6 \mathrm{~mm}$ diameter sterile paper disks, previously impregnated with $10 \mu \mathrm{L}$ of pure CZEO, were placed on the plates and incubated for $24 \mathrm{~h}$ at $37^{\circ} \mathrm{C}$. The diameter of the inhibition zone was measured in millimeters using a caliper.

\subsubsection{Minimum Inhibitory Concentration (MIC) and Minimum Bactericidal Concentration (MBC)}

MICs values were determined using the broth microdilution assay in 96-well polystyrene microtiter plates with round bottom (KASVI, São José dos Pinhais, Paraná, Brazil). First, all wells were filled with $100 \mu \mathrm{L}$ of CZEO prepared in TSB in a 2-fold reduction concentration from 4000 to $125 \mu \mathrm{g} / \mathrm{mL}$. Then, $100 \mu \mathrm{L}$ of the bacterial suspension at $1 \times 10^{6} \mathrm{CFU} / \mathrm{mL}$ were 
added to each well, and the plate was incubated at $37^{\circ} \mathrm{C}$ under aerobic conditions. After $24 \mathrm{~h}$, the lowest concentration of EO that completely inhibited the bacterial growth was considered as MIC [36]. MBCs were determined in broth dilution tests by sub-culturing $10 \mu \mathrm{L}$ from the wells where there was no visible microbial growth to plates containing TSB Agar. The plates were incubated for $24 \mathrm{~h}$ at $37^{\circ} \mathrm{C}$ under aerobic conditions. Then, the lowest concentration of CZEO that decreased $99.9 \%$ of the bacterial population was considered as MBC.

\subsection{CZEO Antibiofilm Activity}

4.6.1. Biofilm Formation

The CZEO activity to inhibit the biofilm formation was analyzed as the minimal concentration able to prevent the initial adhesion and biofilm development on polystyrene surface (O'Toole, 2011). A serial 2-fold dilutions of CZEO at sub inhibitory concentrations (subMIC, $\frac{1}{4}-, \frac{1}{2}$ - and 1-fold MIC) were prepared at $100 \mu \mathrm{L}$ of final volume in 96 well flatbottom polystyrene microtiter plates. Next, $100 \mu \mathrm{L}$ of a cell suspension at $10^{6} \mathrm{CFU} / \mathrm{mL}$ prepared in the TSB was added into each well and incubated at $37^{\circ} \mathrm{C}$ for $24 \mathrm{~h}$ under aerobic conditions.

The biofilm biomass was quantified by crystal violet (CV) staining. Firstly, each well was washed thrice with sterile distilled water to remove planktonic cells. After aspiration of unattached cells, biofilms were fixed with $200 \mu \mathrm{L}$ of $95 \%$ methanol (Dinâmica, São Paulo, Brazil) for $10 \mathrm{~min}$ and air-dried at room temperature. Then, $200 \mu \mathrm{L}$ of the $0.1 \% \mathrm{CV}$ solution (Synth ${ }^{\circledR}$, São Paulo, Brazil) were added and incubated for $10 \mathrm{~min}$. The plate was washed three times with saline, and the biomass-linked dye was solubilized in $200 \mu \mathrm{L}$ of $33 \%$ glacial acetic acid (Dinâmica, São Paulo, Brazil). The biofilm was indirectly quantified by measuring the supernatant absorbance after CV solubilization at $590 \mathrm{~nm}$ using an optical density reader (SpectraMax ${ }^{\circledR}$ Paradigm $^{\circledR}$ Molecular Devices, San Jose, CA, USA) at $590 \mathrm{~nm}$.

\subsubsection{Preformed Biofilm}

The mature Staphylococcus biofilm susceptibility to CZEO was evaluated in 96-well polystyrene flat-bottomed microtiter plates. After biofilm formation under aerobic conditions during $24 \mathrm{~h}$ with the $200 \mu \mathrm{L}$ of initial inoculum of $1 \times 10^{6} \mathrm{CFU} / \mathrm{mL}$, the wells were washed three times with saline solution to remove the planktonic and weakly attached cells. Subsequently, the biofilm was treated with $200 \mu \mathrm{L}$ CZEO solutions, ranging from subMIC to 1, 2 and 4-fold MIC. After $24 \mathrm{~h}$ at $37^{\circ} \mathrm{C}$, the content of each well was removed, washed with saline, and the residual biofilm was quantified according to biomass and the number of viable cells by CV staining (described before) and colony forming units (CFU), respectively.

To determine the viable cells in the CZEO-treated biofilm, $200 \mu \mathrm{L}$ of saline solution were added to each well, and the microplate was subjected to ultrasound (GNATUS, São Paulo, Brazil) for $5 \mathrm{~min}$ to detach the biofilm-embedded bacteria. A serial ten-fold dilutions were prepared from the cell suspension, and $10 \mu \mathrm{L}$ were plated in TSB agar. After $24 \mathrm{~h}$ of incubation at $37^{\circ} \mathrm{C}$, the total of enumerated cells was expressed in $\log _{10} \mathrm{CFU} / \mathrm{mL}$ from the average of the number of CFUs of three different wells from the same replicate.

\subsection{Statistical Analyses}

All microbial assays were performed in triplicate on three different days, and the results were presented as the mean \pm standard deviations (SD). Statistical analysis was performed by a one-way analysis of variance (ANOVA) and Tukey post-hoc test using free software R Studio (Integrated Development for R. PBC, Boston, MA, USA). Differences between groups compared to untreated cells were considered significant for ${ }^{*} p<0.05$, ${ }^{* *} p<0.01,{ }^{* * *} p<0.001,{ }^{* * * *} p<0.0001$.

\section{Conclusions}

We have found that CZEO has an effective antimicrobial and antibiofilm activity against Staphylococcal strains and could represent a potential alternative to treat common 
ear infections in canines caused by Staphylococcus spp. However, more studies are needed to characterization the mechanism of action as well as to standardize the best way to use it against the pathogenic bacteria.

Author Contributions: Conceptualization, I.N.G.d.S. and V.A.C.; Data curation, V.d.Q.A., M.N.C.M. and J.A.P.G.; Formal analysis, J.A.P.G., T.H.S.R., G.A.G., D.d.S.C.M.C.-B., I.N.G.d.S. and V.A.C.; Funding acquisition, V.A.C.; Investigation, V.d.Q.A., M.J.C.S., M.N.C.M., R.M.B.C., T.H.S.R., R.F.d.M.G. and D.d.S.C.M.C.-B.; Methodology, V.d.Q.A., M.J.C.S., R.M.B.C. and R.F.d.M.G.; Project administration, V.A.C.; Resources, G.A.G., R.F.d.M.G. and D.d.S.C.M.C.-B.; Supervision, I.N.G.d.S. and V.A.C.; Writing—original draft, V.d.Q.A., M.N.C.M. and I.N.G.d.S.; Writing-review and editing, J.A.P.G. and V.A.C. All authors have read and agreed to the published version of the manuscript.

Funding: This research received no external funding.

Institutional Review Board Statement: The study was approved by the Animal Ethics Committee from University Center INTA (protocol code 2020.04-01-P), being conducted according to the ethical principles involving animal research.

Acknowledgments: The LaBAM team is grateful for Foundation for Scientific and Technological Development Support of Ceará (FUNCAP) and Coordination for the Improvement of Higher Education Personnel (CAPES).

Conflicts of Interest: The authors declare no conflict of interest.

\section{Appendix A}

Table A1. Percentage of the Cinnamomum zeylanicum Essential Oil Chemical Compositions.

\begin{tabular}{|c|c|c|c|}
\hline Identified Components & $\mathrm{KIC}^{1}$ & $\mathrm{KIL}^{2}$ & CZEO $(\%)^{3}$ \\
\hline Benzenoid & & & 0.87 \\
\hline Benzaldehyde & 967 & 960 & 0.87 \\
\hline Monoterpene hydrocarbons & & & 0.68 \\
\hline o-cimene & 1030 & 1026 & 0.34 \\
\hline$\beta$ - Phellandrene & 1036 & 1029 & 0.34 \\
\hline Oxygenated monoterpene & & & 4.92 \\
\hline 1,8 -Cineol & 1039 & 1031 & 1.42 \\
\hline linalool & 1102 & 1096 & 3.5 \\
\hline Phenylpropanoids & & & 90.09 \\
\hline (E)-cinnamaldehyde & 1281 & 1270 & 77.42 \\
\hline eugenol & 1364 & 1359 & 8.17 \\
\hline (E) cinamyl-acetato & 1451 & 1446 & 4.5 \\
\hline Sesquiterpene hydrocarbons & & & 3.44 \\
\hline$\alpha$-Copaene & 1383 & 1376 & 1.91 \\
\hline (E)-Caryophylene & 1428 & 1419 & 1.1 \\
\hline$\delta$-Cadinene & 1531 & 1523 & 0.43 \\
\hline Total identified & & & 100 \\
\hline
\end{tabular}

${ }^{1} \mathrm{KIC}$ : Kovats indices calculated against n-alkanes (C7-C30) on an RTX-5MS column. ${ }^{2}$ KIL: Kovats retention indexes in the literature (ADAMS, 2007). ${ }^{3}$ Percentage of the peak area in relation to the total area of the sample.

\section{References}

1. De Martino, L.; Nocera, F.P.; Mallardo, K.; Nizza, S.; Masturzo, E.; Fiorito, F.; Iovane, G.; Catalanotti, P. An update on microbiological causes of canine otitis externa in Campania Region, Italy. Asian Pac. J. Trop. Biomed. 2016, 6, 384-389. [CrossRef]

2. Penna, B.; Varges, R.; Medeiros, L.; Martins, G.M.; Martins, R.R.; Lilenbaum, W. Species distribution and antimicrobial susceptibility of staphylococci isolated from canine otitis externa. Vet. Dermatol. 2010, 21, 292-296. [CrossRef] [PubMed]

3. Hill, P.B.; Imai, A. The immunopathogenesis of staphylococcal skin infections-A review. Comp. Immunol. Microbiol. Infect. Dis. 2016, 49, 8-28. [CrossRef] [PubMed]

4. Loeffler, A.; Lloyd, D.H. What has changed in canine pyoderma? A narrative review. Vet. J. 2018, 235, 73-82. [CrossRef]

5. Davies, J. Origins and evolution of antibiotic resistance. Microbiologia 1996, 12, 9-16. [CrossRef]

6. Ma, G.C.; Worthing, K.A.; Ward, M.P.; Norris, J.M. Commensal Staphylococci Including Methicillin-Resistant Staphylococcus aureus from Dogs and Cats in Remote New South Wales, Australia. Microb. Ecol. 2020, 79, 164-174. [CrossRef] 
7. Singh, A.; Walker, M.; Rousseau, J.; Weese, J.S. Characterization of the biofilm forming ability of Staphylococcus pseudintermedius from dogs. BMC Vet. Res. 2013, 9, 93. [CrossRef]

8. Yin, W.; Wang, Y.; Liu, L.; He, J. Biofilms: The Microbial “Protective Clothing” in Extreme Environments. Int. J. Mol. Sci. 2019, 20, 3423. [CrossRef]

9. Behbahani, B.A.; Falah, F.; Arab, L.F.; Vasiee, M.; Yazdi, T.F. Chemical Composition and Antioxidant, Antimicrobial, and Antiproliferative Activities of Cinnamomum zeylanicum Bark Essential Oil. Evid.-Based Complement. Altern. Med. 2020, $2020,8$. [CrossRef]

10. Rocha, R.R.; Matos, M.N.C.; Guerrero, J.A.P.; Cavalcante, R.M.B.; Melo, R.S.; Azevedo, Á.M.A.; Pereira, A.M.G.; Lopes, P.H.R.; Rodrigues, T.H.S.; Bandeira, P.N.; et al. Comparative study of the chemical composition, antibacterial activity and synergic effects of the essential oils of Croton tetradenius baill. and C. pulegiodorus baill. against Staphylococcus aureus isolates. Microb. Pathog. 2021, 156, 104934. [CrossRef]

11. Ebani, V.V.; Mancianti, F. Use of essential oils in veterinary medicine to combat bacterial and fungal infections. Vet. Sci. 2020, 7, 193. [CrossRef]

12. Nocera, F.P.; Mancini, S.; Najar, B.; Bertelloni, F.; Pistelli, L.; De Filippis, A.; Fiorito, F.; De Martino, L.; Fratini, F. Antimicrobial activity of some essential oils against methicillin-susceptible and methicillin-resistant Staphylococcus pseudintermedius-associated pyoderma in dogs. Animals 2020, 10, 1782. [CrossRef]

13. Purkait, S.; Bhattacharya, A.; Bag, A.; Chattopadhyay, R.R. Evaluation of antibiofilm efficacy of essential oil components $\beta$ caryophyllene, cinnamaldehyde and eugenol alone and in combination against biofilm formation and preformed biofilms of Listeria monocytogenes and Salmonella typhimurium. Lett. Appl. Microbiol. 2020, 71, 195-202. [CrossRef]

14. Yanakiev, S. Effects of Cinnamon (Cinnamomum spp.) in Dentistry: A Review. Molecules 2020, 25, 4184. [CrossRef]

15. Shen, S.; Zhang, T.; Yuan, Y.; Lin, S.; Xu, J.; Ye, H. Effects of cinnamaldehyde on Escherichia coli and Staphylococcus aureus membrane. Food Control 2015, 47, 196-202. [CrossRef]

16. Melo, R.S.; Azevedo, Á.M.A.; Pereira, A.M.G.; Rocha, R.R.; Cavalcante, R.M.B.; Matos, M.N.C.; Lopes, P.H.R.; Gomes, G.A.; Rodrigues, T.H.S.; Dos Santos, H.S.; et al. Chemical composition and antimicrobial effectiveness of Ocimum gratissimum L. essential oil against multidrug-resistant isolates of Staphylococcus aureus and Escherichia coli. Molecules 2019, 24, 3864. [CrossRef]

17. He, Z.; Huang, Z.; Jiang, W.; Zhou, W. Antimicrobial Activity of Cinnamaldehyde on Streptococcus mutans Biofilms. Front. Microbiol. 2019, 10, 2241. [CrossRef]

18. Davies, J.; Davies, D. Origins and evolution of antibiotic resistance. Microbiol. Mol. Biol. Rev. 2010, 74, 417-433. [CrossRef]

19. Kasai, T.; Fukui, Y.; Aoki, K.; Ishii, Y.; Tateda, K. Changes in the ear canal microbiota of dogs with otitis externa. J. Appl. Microbiol. 2021, 130, 1084-1091. [CrossRef]

20. Zhang, Y.; Liu, X.; Wang, Y.; Jiang, P.; Quek, S.Y. Antibacterial activity and mechanism of cinnamon essential oil against Escherichia coli and Staphylococcus aureus. Food Control 2016, 59, 282-289. [CrossRef]

21. Pieracci, Y.; Ciccarelli, D.; Giovanelli, S.; Pistelli, L.; Flamini, G.; Cervelli, C.; Mancianti, F.; Nardoni, S.; Bertelloni, F.; Ebani, V.V. Antimicrobial activity and composition of five rosmarinus (Now salvia spp. and varieties) essential oils. Antibiotics 2021, 10, 11090. [CrossRef] [PubMed]

22. Ghavam, M.; Manca, M.L.; Manconi, M.; Bacchetta, G. Chemical composition and antimicrobial activity of essential oils obtained from leaves and flowers of Salvia hydrangea DC. ex Benth. Sci. Rep. 2020, 10, 15647. [CrossRef] [PubMed]

23. Chouhan, S.; Sharma, K.; Guleria, S. Antimicrobial Activity of Some Essential Oils-Present Status and Future Perspectives. Medicines 2017, 4, 58. [CrossRef] [PubMed]

24. Chen, H.; Wubbolts, R.W.; Haagsman, H.P.; Veldhuizen, E.J.A. Inhibition and Eradication of Pseudomonas aeruginosa Biofilms by Host Defence Peptides. Sci. Rep. 2018, 8, 10446. [CrossRef]

25. Carneiro, V.A.; de Oliveira, S.T.; Silva, R.L.; Duarte, H.S.; Silva, M.L.; Matos, M.N.C.; Cavalcante, R.M.B.; Figueira, C.S.; Lorenzón, E.N.; Cilli, E.M.; et al. Antimicrobial and antibiofilm activity of Lys-[Trp6]hy-a1 combined with ciprofloxacin against gram-negative bacteria. Protein Pept. Lett. 2020, 27, 1124-1131. [CrossRef]

26. Rossi, M.W.; Heuertz, R.M. Cinnamaldehyde inhibits MRSA biofilm formation and reduces cell viability. Am. Soc. Clin. Lab. Sci. 2017, 30, 214-218. [CrossRef]

27. Verderosa, A.D.; Totsika, M.; Fairfull-Smith, K.E. Bacterial biofilm eradication agents: A current review. Front. Chem. 2019, 7, 824. [CrossRef]

28. Song, C.Y.; Nam, E.H.; Park, S.H.; Hwang, C.Y. In vitro efficacy of the essential oil from Leptospermum scoparium (manuka) on antimicrobial susceptibility and biofilm formation in Staphylococcus pseudintermedius isolates from dogs. Vet. Dermatol. 2013, 24, 404-409. [CrossRef]

29. Dawson, C.C.; Intapa, C.; Jabra-Rizk, M.A. "Persisters": Survival at the cellular level. PLoS Pathog. 2011, 7, e1002121. [CrossRef]

30. Mishra, R.; Panda, A.K.; De Mandal, S.; Shakeel, M.; Bisht, S.S.; Khan, J. Natural anti-biofilm agents: Strategies to control biofilm-forming pathogens. Front. Microbiol. 2020, 11, 566325. [CrossRef]

31. Kaur, M.; Nagpal, M.; Singh, M.; Singh, T.G.; Aggarwal, G.; Dhingra, G.A. Improved antibacterial activity of topical gel-based on nanosponge carrier of cinnamon oil. BioImpacts 2021, 11, 23-31. [CrossRef]

32. Liu, Y.; Wang, S.; Zhang, R.; Lan, W.; Qin, W. Development of poly(Lactic acid)/chitosan fibers loaded with essential oil for antimicrobial applications. Nanomaterials 2017, 7, 194. [CrossRef] 
33. Dingle, T.C.; Butler-Wu, S.M. MALDI-TOF mass spectrometry for microorganism identification. Clin. Lab. Med. 2013, 33, 589-609. [CrossRef]

34. Clinical Laboratory Standards Institute CLSI M100. Performance Standards for Antimicrobial Susceptibility Testing, 29th ed.; CLSI: Wayne, PA, USA, 2019.

35. Adams, R.P. Identification of Essential Oil Components by Gas Chromatography/Mass Spectrometry, 4th ed.; Allured Publishing Corporation: Carroll Stream, IL, USA, 2007.

36. Van Den Dool, H.; Dec Kratz, P. A generalization of the retention index system including linear temperature programmed gas-liquid partition chromatography. J. Chromatogr. A 1963, 11, 463-471. [CrossRef]

37. Clinical and Laboratory Standards Institue CLSI M02. Performance Standards for Antimicrobial Disk Suspectibility Tests, 13th ed.; CLSI: Wayne, PA, USA, 2018.

38. Mith, H.; Duré, R.; Delcenserie, V.; Zhiri, A.; Daube, G.; Clinquart, A. Antimicrobial activities of commercial essential oils and their components against food-borne pathogens and food spoilage bacteria. Food Sci. Nutr. 2014, 2, 403-416. [CrossRef] 